\title{
Use of Herbal Remedies by Hispanic Patients: Do They Inform Their Physician?
}

\author{
Laura Howell, MD, Komal Kochhar, MBBS, MHA, Robert Saywell, Jr., PhD, MPH, \\ Terrell Zollinger, DrPH, Julie Koebler, PharmD, Christina Mandzuk, BSE, \\ Brittany Sutton, MPH, Javier Sevilla-Martir, MD, and Deborab Allen, MD
}

Purpose: This study measured the knowledge and use of herbs among Hispanics and assessed their experiences when discussing herb use with their physician.

Methods: Self-administered questionnaires were collected from 620 Hispanic patients seeking treatment in urban health centers.

Results: Most (80.3\%) reported using herbs. Herb users were more comfortable speaking Spanish (91.9\% vs $80.2 \%)$ and had been in the United States less than 5 years (47.0\% vs $29.4 \%)$. More users considered herbs as drugs $(60.5 \%$ vs $39.6 \%)$. Users were more aware that herbs could harm a baby if taken during pregnancy (56.4\% vs $36.0 \%)$. The majority did not know the English name for 23 of the 25 herbs. A majority indicated their physician was unaware of their herb use. Few (17.4\%) responded that their physicians asked about herb use. Only $41.6 \%$ thought their physician would understand their herb use, and 1.8\% believed their physician would encourage continued use. There were no significant differences between herb users and nonusers in their perception of patient-physician communication levels.

Conclusion: Primary care physicians need to be aware that most Hispanic patients are likely to use herbs. It is important to initiate and encourage discussion of their patient's interest in and use of these therapies. (J Am Board Fam Med 2006;19:566-78.)

The use of complementary and alternative medical therapies (CAM) has dramatically increased in the United States over the past 2 decades. The percentage of Americans using CAM increased from $33.8 \%$ to $42.1 \%$ from 1990 to $1997,,^{1,2}$ and it is believed that the percentage has since increased. Most patients consider herbal remedies to be as safe and effective as patented medicines and continue to use various types of CAM. ${ }^{3}$

The sale of herbal medicines is growing by approximately $20 \%$ per year and is the largest growth area in retail pharmacy, far exceeding conventional medicine. ${ }^{4}$ Educated, young to middle-aged, non-

Submitted 20 March 2006; revised 9 June 2006; accepted 12 June 2006.

From the Department of Family Medicine, Indiana University School of Medicine, Indianapolis, IN (KK, RS, TZ, CM, BS, JS-M, DA); Cincinnati Children's Hospital, Cincinnati, $\mathrm{OH}(\mathrm{LH})$; and Butler University, Indianapolis, IN (JK).

Funding: This study was funded in part by the Marion County Health Department (Indianapolis, IN).

This study was presented as a poster session at the 2005 American Public Health Association, Annual Meeting and Exposition, Philadelphia, PA, on December 10-14, 2005.

Conflict of interest: none declared.

Corresponding author: Robert M. Saywell, Jr., Department of Family Medicine, Indiana University School of Medicine, 1110 West Michigan Street, Long Hospital 247, Indianapolis, IN 46202-5102 (E-mail: rsaywell@iupui.edu). black, and financially well-off women are more likely to use CAM. ${ }^{1-3,5-8}$ Of those regularly taking prescription medicines, nearly $20 \%$ concurrently take at least one herb, a high-dose multivitamin, or both. ${ }^{2,9}$ Patients generally report using CAM to augment their conventional medical care rather than as a result of their dissatisfaction with mainstream medicine. ${ }^{5,10}$

Herbal remedies are generally marketed in the United States as dietary supplements and are regulated as such under the 1994 Dietary Supplement Health and Education Act. ${ }^{9}$ In contrast to conventional drugs, herbal remedies do not undergo rigorous clinical trials and postapproval surveillance to define their effectiveness and relative safety. Consequently, clinical practitioners generally do not have available to them the scientific data needed to weigh the risks and benefits of herbal remedies as they do for conventional pharmaceutical medications. ${ }^{4}$ There is evidence to suggest that herbal remedies may contain ingredients that can worsen medical problems and interact with specific prescription medications.

Studies have estimated that the prevalence of herb use in the United States may be as high as one third $^{1,2,5,6,11}$ and adverse reactions to herbs are 
probably under-recognized and under-reported. , $^{42}$ Oral use of herbs constitutes a greater potential for significant health risk than non-ingested treatment modalities because many herbs may be therapeutic at a low dose but toxic at higher doses. In addition, interactions between herbs and drugs may increase or decrease the pharmacological or toxicological effects of either component in addition to the synergistic therapeutic effects that may complicate the dosing of long-term medications. ${ }^{13}$

Effective physician-patient communication is vital to reduce the dangers of herb-drug interactions. Physicians with an open mind to CAM may be more likely to hear from their patients about their herb use as studies show that as many as one half to two thirds of patients do not tell their physicians about their use of herbs. ${ }^{1,3}$ Knowledge and mutual respect are the foundations of negotiating conflicts that arise from approaching an illness from 2 different belief and value systems. ${ }^{14}$ Recent literature suggests the importance of providing training in CAM to medical students and residents and encouraging them to communicate these issues with patients. ${ }^{4,8,15}$ One study shows that physicians' exhibit better question-asking skills with non-Hispanic white patients, compared with Hispanic patients, and that patient ethnicity did not influence patient reported use or physician-patient communication about $\mathrm{CAM}^{8}{ }^{8}$ It was also observed that resident physicians with less clinical experience were more likely to ask patients one or more questions about their use of CAM. ${ }^{8}$

Even though herb use has increased over the past decade, the number of US pharmacy schools offering courses addressing their use has declined. ${ }^{15}$ According to one study, only 9 of 77 pharmacy colleges maintain pharmacognosy as a course in their curricula. ${ }^{15,16}$ As a result, today's pharmacy school graduates may not be adequately equipped to respond to their patients' request for information on herbs. ${ }^{15}$ Over one-half $(52.0 \%)$ of the patients purchased their herbs in drugstores or groceries, where pharmacists would be available, but none of them received any herb information from the pharmacist. ${ }^{17}$ Another study found that more practicing pharmacists, compared with pharmacy students, felt that pharmacists should not become practitioners of CAM (26.6\% vs $0.0 \%) .{ }^{18}$ This underscores the need for physicians to recognize an even greater responsibility to provide their patients with reliable information about herbs and to be particularly cognizant of the need to do so for their Hispanic population.

Given the potential for adverse reactions and interactions associated with herbs, it is important to identify the prevalence of herb use in specific populations and whether herb users routinely inform their primary care physician of such use. Several studies have indicated that the Hispanic population, as an ethnic group, exhibits high usage of CAM. ${ }^{7,19}$ One study revealed that Mexican-American women were 3 times more likely to use herbs than the general population. ${ }^{19}$ Another study in New Mexico showed that $77 \%$ of surveyed Hispanics used herbs, compared with $47 \%$ of non-Hispanic whites. ${ }^{7}$ Specific reasons why Hispanics may be more likely to use herbs are not clearly understood.

Ferguson and Candib ${ }^{20}$ concluded that minority patients, especially those not proficient in English, were less likely to establish rapport with physicians, less likely to receive sufficient medical information, and less likely to be encouraged to participate in medical decision making. Elder et $\mathrm{al}^{3}$ suggested that patients seek CAM because they cannot afford traditional medications. A distrust of physicians or physicians' negative responses to herb use has also been identified as a reason Hispanic patients' turn to herbs. ${ }^{5}$ Studies have also found that some patients believe that herb use, when combined with traditional therapy, may result in more optimal health outcomes. ${ }^{3}$

Numerous researchers ${ }^{14,17,21-28}$ have examined the unique cultural health beliefs of Hispanic patients, including the use of folk healing or herbs. However, few studies ${ }^{17,19,29,30}$ have actually surveyed Hispanic patients regarding their attitudes about herbs and their comfort level when discussing such remedies with their physicians. No studies have been conducted in Indiana, a Midwestern state with a rapidly growing Hispanic population. The goals of this study were to 1) assess Hispanic patients' knowledge about herbs, 2) explore the underlying reasons why these patients may be more likely to use herbs than the general population, 3) examine patients' comfort levels with discussing their herb use with their physicians, and 4) determine the extent to which physicians inquire about their patients' herb use.

\section{Methods}

A patient survey was conducted between October 2003 and February 2004 at 5 urban health centers 
in Indianapolis, IN, that treat high numbers of Hispanic patients. The patients were approached in the waiting room of health clinics by bilingual research assistants. The research assistants identified the Hispanic patients visually by their ethnic appearance and asked each of them (if older than 18 years of age) to participate. At no time did the research assistants examine patients' medical records or ask medical staff the ethnicity of patients. It is not known how many patients refused to participate. All self-identified Hispanic patients over the age of 18 , who visited the study clinic sites during the data collection period were asked by bilingual research assistants to complete a survey as they waited to see their physician. The survey instrument included questions about the patient's demographic information, familiarity with various specific herbs, attitudes toward and beliefs about herbs, and the patient's comfort level when discussing herb use with their physician. The survey instrument was initially created in English, and then translated into Spanish by an individual with a medical background whose first language was Spanish. It was then given to another medically experienced individual fluent in Spanish who translated it into English to ensure concept equivalency. The Spanish version of the survey instrument was also examined by numerous members of the Indianapolis Hispanic community to ensure that questions were asked appropriately and with cultural sensitivity. Research assistants interviewed patients if they were unable to read the survey instrument. Survey completion was voluntary, no incentives were provided, and the subjects were assured that their responses would be kept confidential. The study received Indiana University Institutional Review Board approval in May 2003.

Completed questionnaires were scanned into an electronic data file, verified by a research assistant and analyzed using SPSS version 12.0.1. Descriptive statistics including mean, median, and frequency distribution were calculated. $\chi^{2}$ tests were performed to determine significant statistical differences. Values of $P$ less than .05 were considered statistically significant.

\section{Results}

\section{Demographic and Clinical Characteristics}

A total of 620 Hispanic individuals completed the herb use questionnaire. The herbs used in the sur- vey instrument were chosen by a consensus of numerous Hispanic individuals interviewed in the community as to what were the most common herbs used. Most often, the respondents were female $(78.7 \%)$, unemployed $(56.8 \%)$, uninsured (69.7\%) and had lived in the United States for less than 5 years $(43.9 \%)$. One half $(58.9 \%)$ of the respondents were in their 20s, whereas approximately one tenth $(12.2 \%)$ were over age 40 . More than one half $(53.0 \%)$ did not have a high school degree, and nearly one half (48.8\%) lived with their spouse. More than one fourth $(25.4 \%)$ had at least one child living in their household with a mean household size of 4.16. More than four fifths (89.2\% and $89.9 \%$, respectively) were most comfortable reading and speaking Spanish rather than English. Less than one third (29.8\%) had not seen a physician in the past year, whereas more than one third $(35.5 \%)$ had seen a physician at least 3 times in the past year. A majority (90.1\%) had not seen a curandero or bierbero in the past year.

\section{Use of Herbal Remedies}

Four fifths $(80.3 \%)$ responded that they were currently taking or had taken an oral herbal remedy in the past. Two thirds (59.6\%) had taken between 6 and 15 different herbs during their lifetime. One third $(30.7 \%)$ indicated they obtained their herbs from a Hispanic grocery store. Some indicated that herbs were most often used to treat cough $(26.3 \%)$, stomach pain $(24.9 \%)$, sore throat $(20.3 \%)$, menstrual cramps $(19.1 \%)$, headache $(8.8 \%)$, and chest pain $(7.2 \%)$.

Participants were asked about their use and knowledge of the English names for 25 commonly used herbs for treatment purposes (not as food seasonings) and whether their physicians were aware of their use, as shown in Table 1. More than half of the respondents reported that they had used at least 1 of 10 herbs among the 25 listed. The 10 most commonly used herbs were cinnamon, cloves, cumin, chamomile, garlic, onion, grass syrup, aloe vera, oregano, and lemon. The majority of respondents did not know the English name for 23 of the 25 herbs on the list. The 2 herbs for which the majority knew the English name were spider milkweed and bitter gourd. A vast majority of the respondents indicated that their doctors were unaware of their herb use.

Table 2 presents the demographic characteristics of the herb users and non-users. Of the 8 


\begin{tabular}{|c|c|c|c|c|c|c|}
\hline & \multicolumn{2}{|c|}{ Have Used the Herb } & \multicolumn{2}{|c|}{ Know English Name } & \multicolumn{2}{|c|}{ Doctor Aware I Use } \\
\hline & Number & $\%$ & Number & $\%$ & Number & $\%$ \\
\hline Immortal (Spider Milkweed) & 7 & 1.4 & 5 & 71.4 & 3 & 42.9 \\
\hline Plumajillo (Pleurisy Root) & 16 & 3.2 & 6 & 37.5 & 5 & 31.3 \\
\hline Canela (Cinnamon) & 415 & 83.3 & 81 & 19.5 & 22 & 5.3 \\
\hline Clavo (Cloves) & 292 & 58.6 & 27 & 9.2 & 8 & 2.7 \\
\hline Comino (Cumin) & 295 & 59.2 & 27 & 9.2 & 14 & 4.7 \\
\hline Eucalipto (Eucalyptus) & 214 & 43.0 & 30 & 14.0 & 20 & 9.3 \\
\hline Manzanilla (Chamomile) & 421 & 84.5 & 54 & 12.8 & 45 & 10.7 \\
\hline Ajo (Garlic) & 368 & 73.9 & 65 & 17.7 & 22 & 6.0 \\
\hline Jengibre (Ginger) & 116 & 23.3 & 38 & 32.8 & 16 & 13.8 \\
\hline Cebolla (Onion) & 352 & 70.7 & 88 & 25.0 & 19 & 5.4 \\
\hline Granada (Pomegranate) & 165 & 33.1 & 23 & 13.9 & 15 & 9.1 \\
\hline Yerba Buena (Grass Syrup) & 353 & 70.9 & 38 & 10.8 & 24 & 6.8 \\
\hline Anis Estrella (Star Anise) & 131 & 26.3 & 22 & 16.8 & 17 & 13.0 \\
\hline Estafiate (Wormwood) & 83 & 16.7 & 12 & 14.5 & 10 & 12.0 \\
\hline Siete Jarabes (Seven Syrups) & 29 & 5.8 & 13 & 44.8 & 11 & 37.9 \\
\hline Cundeamore (Bitter Gourd) & 14 & 2.8 & 11 & 78.6 & 6 & 42.9 \\
\hline Savila (Aloe Vera) & 261 & 52.4 & 34 & 13.0 & 18 & 6.9 \\
\hline Una de Gato (Cat's Claw) & 62 & 12.4 & 15 & 24.2 & 12 & 19.4 \\
\hline Pelos de Elote (Corn Silk) & 140 & 28.1 & 21 & 15.0 & 16 & 11.4 \\
\hline Tlanchalagua (Tea) & 31 & 6.2 & 15 & 48.4 & 11 & 35.5 \\
\hline Oregano & 322 & 64.7 & 41 & 12.7 & 22 & 6.8 \\
\hline Limon (Lemon) & 378 & 75.9 & 82 & 21.7 & 22 & 5.8 \\
\hline Valeriana (Valerian) & 66 & 13.3 & 19 & 28.8 & 10 & 15.2 \\
\hline Tomillo (Thyme) & 137 & 27.5 & 12 & 8.8 & 9 & 6.6 \\
\hline Epasote (Wormseed) & 220 & 44.2 & 8 & 3.6 & 6 & 2.7 \\
\hline
\end{tabular}

* Number using the herb/total number of herb users [7/498 $\cdot 100=1.4]$.

${ }^{* *}$ Number knowing the English name/number using the herb $[5 / 7 \cdot 100=71.4]$.

*** Number indicating Doctor is aware/number using the herb $[3 / 7 \cdot 100=42.9]$.

variables included in the analysis, only 2 -language and duration of residence in the United Stateswere significantly different between the 2 groups. Herb users were more comfortable speaking Spanish than English (91.9\% vs $80.2 \%$ ) and more often lived in the United States for less than 5 years (47.0\% vs $29.4 \%$ ). The remaining 6 characteristics: gender, age, education level, employment status, health insurance coverage, and number of physician visits in the past year were not significantly different between the herb users and nonusers. Two multiple logistic regression models were developed to determine the extent to which demographic characteristics explain the use of herbal remedies and whether or not the individual informed their physician of their herb use. None of the findings were found to be statistically significant.

\section{Knowledge and Use of Herbs}

Table 3 shows that the overall knowledge about herbs was lacking among the participants. More than half of the respondents felt that herbs were drugs $(58.2 \%)$ and that some herbs could harm a baby if taken during pregnancy (54.3\%). Herb users were significantly more likely than nonusers to know that herbs are drugs $(60.5 \%$ vs $39.6 \%)$ and that herbs could harm a baby if taken during pregnancy $(56.4 \%$ vs $36.0 \%)$. One third believed that some herbs could interact with prescription medications $(35.1 \%)$ and that herbs were not safe to use during pregnancy, compared with prescription or over-the-counter drugs (35.3\%).

More than two thirds $(66.0 \%)$ indicated that a family member recommended they take herbs. Four in $10(44.0 \%)$ indicated they had given their children or grandchildren herbs. Herb users were 


\begin{tabular}{|c|c|c|c|c|c|}
\hline & \multicolumn{2}{|c|}{ Yes $(\mathrm{N}=498)$} & \multicolumn{2}{|c|}{ No $(N=122)$} & \multirow[b]{2}{*}{$P$ Value } \\
\hline & Number & $\%$ & Number & $\%$ & \\
\hline $\begin{array}{l}\text { Do you currently take or have you ever taken an oral herbal } \\
\text { remedy? }\end{array}$ & 498 & 80.3 & 122 & 19.7 & \\
\hline Which language do you feel most comfortable speaking? & & & & & .001 \\
\hline Spanish & 441 & 91.9 & 77 & 80.2 & \\
\hline English & 15 & 3.1 & 10 & 10.4 & \\
\hline Both & 24 & 5 & 9 & 9.4 & \\
\hline Missing & 18 & & 26 & & \\
\hline What is your gender? & & & & & .375 \\
\hline Male & 99 & 20.6 & 26 & 24.5 & \\
\hline Female & 381 & 79.4 & 80 & 75.5 & \\
\hline Missing & 18 & & & 16.0 & \\
\hline What is your age? & & & & & .477 \\
\hline 0 to 20 & 52 & 10.5 & 12 & 10.6 & \\
\hline 21 to 24 & 130 & 26.4 & 28 & 24.8 & \\
\hline 25 to 29 & 113 & 23.1 & 22 & 19.4 & \\
\hline 30 to 34 & 90 & 18.2 & 17 & 15.0 & \\
\hline 35 to 39 & 38 & 7.6 & 15 & 13.4 & \\
\hline$\geq 40$ & 70 & 14.2 & 19 & 16.8 & \\
\hline Missing & 5 & & 9 & & \\
\hline What is the highest level of education you completed? & & & & & .269 \\
\hline Less than High School & 218 & 52.7 & 46 & 54.8 & \\
\hline High School & 153 & 37.0 & 34 & 40.5 & \\
\hline College or above & 43 & 10.4 & 4 & 4.8 & \\
\hline Missing & 84 & & 38 & & \\
\hline \multicolumn{6}{|l|}{ Are you currently working? } \\
\hline Yes & 203 & 42.3 & 47 & 47.5 & .343 \\
\hline No & 277 & 57.7 & 52 & 52.5 & \\
\hline Missing & & & 23 & & \\
\hline Do you have health insurance? & & & & & .760 \\
\hline Yes & 141 & 30.0 & 30 & 31.6 & \\
\hline No & 329 & 70.0 & 65 & 68.4 & \\
\hline Missing & & & 27 & & \\
\hline How many times have you seen a medical doctor in the past year? & & & & & .534 \\
\hline None & 128 & 29.8 & 23 & 29.5 & \\
\hline One to two times & 145 & 33.8 & 31 & 39.7 & \\
\hline Three or more times & 156 & 36.4 & 24 & 30.8 & \\
\hline Missing & 69 & & 44 & & \\
\hline How long have you lived in the United States? & & & & & .000 \\
\hline Less than 5 years & 207 & 47.0 & 27 & 29.4 & \\
\hline 5 years or more & 234 & 53.0 & 65 & 70.6 & \\
\hline Missing & 57 & & 30 & & \\
\hline
\end{tabular}

significantly more likely than nonusers to reveal that a family member recommended that they take herbs (69.7\% vs $39.7 \%$ ) and that they provide herbs to their children or grandchildren ( $46.0 \%$ vs $23.1 \%)$.

\section{Physician Communication and Perceived Attitudes}

Approximately three fourths $(72.7 \%)$ indicated that they were able to communicate easily with their doctors, as shown in Table 4. However, nearly three fourths $(73.7 \%)$ of the respondents reported that their doctors did not ask them about their use of herbs, and a majority $(90.2 \%)$ indicated that their doctor never recommended they take herbs. Majority felt their physician took time to listen to them at each appointment (83.8\%); understood their cultural background 


\begin{tabular}{|c|c|c|c|c|c|c|c|}
\hline & \multicolumn{2}{|c|}{$\begin{array}{c}\text { Users } \\
(\mathrm{N}=498)\end{array}$} & \multicolumn{2}{|c|}{$\begin{array}{l}\text { Non Users } \\
(\mathrm{N}=122)\end{array}$} & \multicolumn{2}{|c|}{$\begin{array}{c}\text { Total } \\
(\mathrm{N}=620)\end{array}$} & \multirow[b]{2}{*}{$P$ Value } \\
\hline & Number & $\%$ & Number & $\%$ & Number & $\%$ & \\
\hline Herbal remedies are drugs & & & & & & & .012 \\
\hline No & 65 & 15.1 & 14 & 26.4 & 79 & 16.4 & \\
\hline Yes & 260 & 60.5 & 21 & 39.6 & 281 & 58.2 & \\
\hline Do not know & 105 & 24.4 & 18 & 34.0 & 123 & 25.5 & \\
\hline Missing & 68 & & 69 & & 137 & & \\
\hline $\begin{array}{l}\text { Some herbal remedies can interact with prescription } \\
\text { medications }\end{array}$ & & & & & & & .327 \\
\hline No & 74 & 17.1 & 9 & 17.0 & 83 & 17.0 & \\
\hline Yes & 157 & 36.2 & 14 & 26.4 & 171 & 35.1 & \\
\hline Do not know & 203 & 46.8 & 30 & 56.6 & 233 & 47.8 & \\
\hline Missing & 64 & & 69 & & 133 & & \\
\hline $\begin{array}{l}\text { Some herbal remedies can harm a baby if taken } \\
\text { during pregnancy }\end{array}$ & & & & & & & .016 \\
\hline No & 37 & 8.4 & 8 & 16.0 & 45 & 9.2 & \\
\hline Yes & 247 & 56.4 & 18 & 36.0 & 265 & 54.3 & \\
\hline Do not know & 154 & 35.2 & 24 & 48.0 & 178 & 36.5 & \\
\hline Missing & 60 & & 72 & & 132 & & \\
\hline $\begin{array}{l}\text { Herbal remedies are safer to use during pregnancy } \\
\text { than prescription or over-the-counter drugs }\end{array}$ & & & & & & & .917 \\
\hline No & 154 & 35.5 & 17 & 33.3 & 171 & 35.3 & \\
\hline Yes & 84 & 19.4 & 11 & 21.6 & 95 & 19.6 & \\
\hline Do not know & 196 & 45.2 & 23 & 45.1 & 219 & 45.2 & \\
\hline Missing & 64 & & 71 & & 135 & & \\
\hline $\begin{array}{l}\text { My family member has recommended an herbal } \\
\text { remedy for me to take }\end{array}$ & & & & & & & .000 \\
\hline No & 122 & 29.6 & 33 & 56.9 & 155 & 33.0 & \\
\hline Yes & 287 & 69.7 & 23 & 39.7 & 310 & 66.0 & \\
\hline Do not know & 3 & 0.7 & 2 & 3.4 & 5 & 1.1 & \\
\hline Missing & 86 & & 64 & & 150 & & \\
\hline $\begin{array}{l}\text { I have given my children (or grandchildren) herbal } \\
\text { remedies }\end{array}$ & & & & & & & .004 \\
\hline No & 194 & 50.5 & 37 & 71.2 & 231 & 53.0 & \\
\hline Yes & 180 & 46.0 & 12 & 23.1 & 192 & 44.0 & \\
\hline Do not know & 10 & 2.6 & 3 & 5.8 & 13 & 3.0 & \\
\hline Missing & 114 & & 70 & & 184 & & \\
\hline
\end{tabular}

(58.9\%); and worked with them to improve their health $(74.1 \%)$. More than two thirds $(71.6 \%)$ indicated that if they went to a curandero for treatment, they would tell their doctor about it. Three fourths $(77.6 \%)$ felt that "they can tell their doctor anything." There were no significant differences noted between the user and nonuser groups.

When asked what they tell their doctors about their use of herbs, one sixth (15.0\%) responded that "I would tell my doctor about all the remedies that I use." When asked what would happen if they told their doctors that they use herbs, only 4 in 10
(41.8\%) indicated that their doctor would understand their herb use. More than one-quarter $(25.9 \%)$ responded that their doctors would not know what the herb was used for and 20.5\% thought that their doctor would tell them to stop using all herbs. One in $10(10.5 \%)$ believed that their doctor would encourage them to continue using herbs; few (1.4\%) thought their doctors would ridicule them for using herbs.

Some of the more commonly used herbs and their potential drug interactions are presented in Table $5 .^{32-34}$ 


\begin{tabular}{|c|c|c|c|c|c|c|c|}
\hline & \multicolumn{2}{|c|}{$\begin{array}{c}\text { Users } \\
(\mathrm{N}=498)\end{array}$} & \multicolumn{2}{|c|}{$\begin{array}{l}\text { Non Users } \\
(\mathrm{N}=122)\end{array}$} & \multicolumn{2}{|c|}{$\begin{array}{c}\text { Total } \\
(\mathrm{N}=620)\end{array}$} & \multirow[b]{2}{*}{$P$ Value } \\
\hline & Number & $\%$ & Number & $\%$ & Number & $\%$ & \\
\hline \multicolumn{7}{|l|}{ I am able to communicate easily with my doctor } & .573 \\
\hline No & 76 & 20.2 & 10 & 19.2 & 86 & 20.1 & \\
\hline Yes & 271 & 72.1 & 40 & 76.9 & 311 & 72.7 & \\
\hline Do not know & 29 & 7.7 & 2 & 3.8 & 31 & 7.2 & \\
\hline Missing & 122 & & 70 & & 192 & & \\
\hline \multicolumn{8}{|l|}{ I feel that I can tell my doctor anything } \\
\hline No & 52 & 13.4 & 7 & 13.2 & 59 & 13.4 & .995 \\
\hline Yes & 301 & 77.6 & 41 & 77.4 & 342 & 77.6 & \\
\hline Do not know & 35 & 9.0 & 5 & 9.4 & 40 & 9.1 & \\
\hline Missing & 110 & & 69 & & 179 & & \\
\hline \multicolumn{8}{|l|}{ My doctor asks me whether I am using any herbal remedies } \\
\hline No & 310 & 74.3 & 35 & 68.6 & 345 & 73.7 & .081 \\
\hline Yes & 73 & 17.5 & 7 & 13.7 & 80 & 17.1 & \\
\hline Do not know & 34 & 8.2 & 9 & 17.6 & 43 & 9.2 & \\
\hline Missing & 81 & & 71 & & 152 & & \\
\hline \multicolumn{7}{|l|}{ My doctor has recommended an herbal remedy for me to take } & .631 \\
\hline No & 362 & 89.8 & 54 & 93.1 & 416 & 90.2 & \\
\hline Yes & 24 & 6.0 & 3 & 5.2 & 27 & 5.9 & \\
\hline Do not know & 17 & 4.2 & 1 & 1.7 & 18 & 3.9 & \\
\hline Missing & 95 & & 64 & & 159 & & \\
\hline \multicolumn{7}{|l|}{ My doctor takes time to listen to me at each appointment } & .823 \\
\hline No & 36 & 9.0 & 5 & 9.3 & 41 & 9.0 & \\
\hline Yes & 338 & 84.1 & 44 & 81.5 & 382 & 83.8 & \\
\hline Do not know & 28 & 7.0 & 5 & 9.3 & 33 & 7.2 & \\
\hline Missing & 96 & & 68 & & 164 & & \\
\hline \multicolumn{7}{|l|}{ My doctor understands my cultural background } & .243 \\
\hline No & 42 & 11.7 & 9 & 19.1 & 51 & 12.6 & \\
\hline Yes & 211 & 58.8 & 28 & 59.6 & 239 & 58.9 & \\
\hline Do not know & 106 & 29.5 & 10 & 21.3 & 116 & 28.6 & \\
\hline Missing & 139 & & 75 & & 214 & 52.7 & \\
\hline \multicolumn{7}{|l|}{$\begin{array}{l}\text { My doctor works with me (and my family) to improve my } \\
\text { health }\end{array}$} & .525 \\
\hline No & 52 & 14.2 & 9 & 19.6 & 61 & 14.8 & \\
\hline Yes & 275 & 74.9 & 31 & 67.4 & 306 & 74.1 & \\
\hline Do not know & 40 & 10.9 & 6 & 13.0 & 46 & 11.1 & \\
\hline Missing & 131 & & 76 & & 207 & & \\
\hline \multicolumn{7}{|l|}{$\begin{array}{l}\text { If I went to a curandero for treatment, I would tell my } \\
\text { doctor about it }\end{array}$} & .531 \\
\hline No & 44 & 11.6 & 9 & 17.0 & 53 & 12.2 & \\
\hline Yes & 274 & 72.1 & 36 & 67.9 & 310 & 71.6 & \\
\hline Do not know & 62 & 16.3 & 8 & 15.1 & 70 & 16.2 & \\
\hline \multirow[t]{2}{*}{ Missing } & 118 & & 69 & & 187 & & \\
\hline & & & & & & Number & $\%$ \\
\hline \multicolumn{8}{|c|}{ Only those who "use" or "ever used" herbal remedies, were asked the following questions: } \\
\hline \multicolumn{8}{|c|}{ What do you tell your doctor about your use of herbal remedies? } \\
\hline \multicolumn{6}{|l|}{ I would tell my doctor about all the remedies that I use } & 37 & 15.0 \\
\hline \multicolumn{6}{|l|}{ I would tell my doctor about some of the remedies that I use } & 46 & 18.7 \\
\hline My doctor never asks whether I use any herbs & & & & & & 163 & 66.3 \\
\hline Missing & & & & & & 252 & \\
\hline What would happen if you told your doctor that you use herba & 1 remedies? & & & & & & \\
\hline My doctor would understand the use of these remedies & & & & & & 92 & 41.8 \\
\hline My doctor would not know what these herbal remedies ar & used for & & & & & 57 & 25.9 \\
\hline My doctor would tell me to stop using all herbal remedies & & & & & & 45 & 20.5 \\
\hline My doctor would encourage me to keep using the remedie & s that are $s$ & & & & & 23 & 10.5 \\
\hline My doctor would ridicule me & & & & & & 3 & 1.4 \\
\hline Missing & & & & & & 278 & \\
\hline
\end{tabular}


Table 5. Continued

\section{Herb}

Jengibre (Ginger)

Granada (Pomegranate)

Anis Estrella (Star Anise)

Estafiate (Wormwood)

Cundeamore (Bitter Gourd)

Savila (Aloe Vera)
Potential Interactions with Prescription Medications

Use

Antiplatelet and anticoagulant agents; antidiabetic agents; calcium channel blockers dyspepsia, flatulence, chemotherapy-induced nausea, rheumatoid arthritis, osteoarthritis, loss of appetite, post-operative nausea and vomiting, migraine headache, anorexia, upper respiratory tract infections, cough, bronchitis, and as a diaphoretic, diuretic, and a stimulant. Fresh ginger: Orally, for treating acute bacterial dysentery, baldness, malaria, orchitis, poisonous snake bites, rheumatism, and toothaches. Dried ginger: orally, for chest pain, low back pain, and stomach pain. Topically, for thermal burns and as an analgesic. In foods and beverages, as a flavoring agent. In manufacturing, as a fragrance component in soaps and cosmetics.

Orally, for hypertension, heart failure, myocardial ischemia, atherosclerosis, hyperlipidemia, acidosis, hemorrhage, HIV disease, tapeworm infestations, diarrhea, dysentery, and opportunistic intestinal worms; for preventing prostate cancer, and as an astringent and abortifacient; for chronic obstructive pulmonary disease, influenza, stomatitis, periodontal disease, erectile dysfunction, diabetes, and cancer.

Topically, as a gargle for sore throat and to treat hemorrhoids.

Orally, for respiratory infections and inflammation, influenza, avian flu, gastrointestinal upset, flatulence, loss of appetite, infant colic, cough, and bronchitis; for increasing milk secretion, promoting menstruation, facilitating childbirth, increasing libido, and treating symptoms of male climacteric. Through inhalation, for respiratory tract congestion. In foods and beverages, as a culinary spice and flavoring agent. In manufacturing, as a fragrance component in soaps, cosmetics, perfumes, and toothpaste, and to mask undesirable odors in drug products.

Orally, for loss of appetite, indigestion and digestive disorders, biliary dyskinesia, fever, and liver disease; as an anthelmintic, aphrodisiac, tonic, antispasmodic, and to stimulate sweating and the imagination. Topically, for healing wounds and insect bites and as a counterirritant. In foods, wormwood as a flavoring agent. In manufacturing, as a fragrance component in soaps, cosmetics, and perfumes, and as an insecticide.

Orally, for diabetes, psoriasis, gastrointestinal upset, ulcers, colitis, constipation, intestinal worms, kidney stones, fever, hepatic disease, and to induce menstruation. Topically, for skin abscesses and wounds, and anorectal herpes lesions.

Orally, for osteoarthritis, inflammatory bowel diseases, fever, itching and inflammation, as a general tonic, for gastroduodenal ulcers, diabetes, asthma, and radiation-related mucositis.

Topically, for burns, wound healing, psoriasis, sunburn, frostbite, inflammation, osteoarthritis, and cold sores; and as an antiseptic and a moisturizer.
Antiplatelet and anticoagulant agents; antidiabetic agents; ACE inhibitors; antihypertensive agents; cytochrome P450 3a4 (Cyp3a4) substrates (eg., lovastatin, itraconazole, ketoconazole, fexofenadine, triazolam, etc.); cytochrome $\mathrm{P} 450$ 2D6 (CYP2D6) substrates (eg, amitriptyline, fluoxetine, codeine, tramadol, ondansetron, etc.)

None known

Anticonvulsants

Antidiabetic agents

Oral medications (in general); sevoflurane; diuretics; digoxin; antidiabetic agents

(Table continues) 
Table 5. Continued

\begin{tabular}{lrr}
\hline Herb & Use & Potential Interactions with Prescription \\
Medications & Medictions
\end{tabular}

Una de Gato (Cat's Claw)

Pelos de Elote (Corn Silk)

Oregano

Limon (Lemon)

Valeriana (Valerian)

Tomillo (Thyme)

Epasote (Wormseed)
Orally, for diverticulitis, peptic ulcers, colitis, gastritis, hemorrhoids, parasites, Alzheimer's disease, chronic fatigue syndrome, wound healing, arthritis, asthma, allergic rhinitis, cancer (especially of the urinary tract), glioblastoma, gonorrhea, dysentery, birth control, bone pain, "cleansing" the kidneys, and viral infections, including herpes zoster, herpes simplex, and human immunodeficiency virus (HIV).

Orally, for cystitis, urethritis, nocturnal enuresis, prostatitis, inflammation of the urinary tract, diabetes, hypertension, and as a diuretic for congestive heart failure.

Orally, for respiratory tract disorders, including cough, asthma, croup, and bronchitis; for gastrointestinal disorders, such as dyspepsia and bloating; for dysmenorrhea, rheumatoid arthritis, urinary tract infections, headaches, heart conditions, intestinal parasites, allergies, sinusitis, arthritis, cold and flu, earaches, and fatigue. Topically, for acne, athlete's foot, dandruff, insect and spider bites, canker sores, gum disease, toothaches, psoriasis, seborrhea, ringworm, rosacea, muscle pain, varicose veins, and warts, and as an insect repellent. In foods and beverages, as a culinary spice and a preservative.

Orally, as a source of vitamin $\mathrm{C}$ in the treatment of scurvy and colds; as a digestive aid, an antiinflammatory, diuretic, and to improve vascular permeability. In foods, as a food and flavoring agent.

Orally, as a sedative-hypnotic for insomnia and as an anxiolytic for restlessness; for mood disorders such as depression, mild tremors, epilepsy, attention deficit-hyperactivity disorder, and chronic fatigue syndrome; for muscle and joint pain, asthma, hysterical states, excitability, hypochondria, headaches, migraine, stomach upset, menstrual cramps and symptoms associated with menopause, including hot flashes and anxiety. Topically, as a bath additive for restlessness and sleep disorders. In manufacturing, as flavoring in foods and beverages.

Orally, for bronchitis, pertussis, sore throat, colic, arthritis, dyspepsia, gastritis, diarrhea, enuresis, dyspraxia, flatulence, skin disorders, as a diuretic, urinary disinfectant, anthelmintic, and as an appetite stimulant. Topically, for laryngitis, tonsillitis, stomatitis, and halitosis; as a counterirritant, an antiseptic in mouthwashes and liniments, and for alopecia areata. Otically, as an antibacterial and antifungal ingredient. In foods, as a flavoring agent. In manufacturing, in perfumes, soaps, cosmetics, and toothpastes.
Antihypertensive agents; immunosuppressants; cytochrome P450 3a4 (Cyp3a4) substrates (eg, lovastatin, itraconazole, ketoconazole, fexofenadine, triazolam, etc.)

Antihypertensive agents; antidiabetic agents; diuretics; corticosteroids; warfarin

None known

None known

Alcohol; benzodiazepines; CNS depressants; cytochrome P450 3a4 (Cyp3a4) substrates (eg, lovastatin, itraconazole, ketoconazole, fexofenadine, triazolam, etc.)

Antiplatelet and anticoagulant agents

None known

\section{Discussion}

The majority of Hispanics who participated in the survey were herb users and it seems that their physicians were generally unaware of their herb use. The herb users tended to be more comfortable speaking Spanish rather than English and had been in the United States for less than 5 years indicating that they may have problems communicating with their physician and/or may not have a good understanding of the health care system in the United 
States. The fact that many did not know the English term for the herbs they use is further evidence of the existence of a barrier to achieving appropriate communications with their physician. Gordon ${ }^{14}$ found that newly arrived Hispanics who were primarily from rural areas were more likely to hold traditional beliefs and values, whereas US-born Hispanics were likely to have more assimilated attitudes, which may explain the higher rate of herb use in recent immigrants.

Elder et $\mathrm{al}^{3}$ pointed out that the main reason given for using herbs, alone or in combination with prescribed medications, was a belief that herbs would be effective. Many of those who communicated with their physician spoke of acceptance and control, but those who did not communicate with their physician mentioned traditional medicine's limitations and the narrow-mindedness of their physicians. ${ }^{3}$ Patients who chose to reveal details about their herb use did so because they perceived their physician would be respectful, open-minded, and willing to listen to them. ${ }^{31}$ Patients found it easier to discuss their use of CAM when they believed that their physician expected them to be using herbs. ${ }^{31}$ On the other hand, patients who chose not to reveal their herb use with their physician gave several reasons for their decision, such as the impression that their physician would be disinterested in their herb use; the anticipation of a negative response; the conviction that their physician would be unwilling or unable to contribute useful information; and the impression that their physician perceives herbs to be irrelevant in the biomedical treatment course. ${ }^{31}$ In addition, patients may feel intimidated by their physicians and perceive a sense of disapproval with regard to their physician's views on their use of CAM. ${ }^{35}$ Similar concerns were expressed by participants in this study. The majority of respondents noted that their physician would not know what the herbs were used for, and one fourth felt that their physician would ridicule them for using herbs.

Eisenberg et $\mathrm{al}^{1}$ noted that $70 \%$ of patients do not reveal their herb use to their allopathic practitioners. The current study indicated that for some herbs, this percentage may be much higher, as only $15 \%$ indicated that they would tell their doctor about all the herbs they use whereas three fourths replied that they could "tell their doctor anything." Providing herb use information to ones' physician was not considered important to the patient; only one third of the respondents were aware that herbs could interact with prescription medication. Regardless of whether patients plan to inform their provider about herb use or not, the onus is on providers to ask the question of their patients. ${ }^{36}$

This study presents the findings of a survey and is subject to the limitations of self-reported data. Most of the survey items were value neutral. However, undoubtedly the respondents would want to appear to be knowledgeable and may have misstated their actual herb use. In addition, because this survey was administered in health care clinics, the responses to items relating to physician communication may have over-represented the level of communication between providers and patients.

Approximately one fourth of the participants who answered the first few pages of the survey did not complete the last part. There are at least 2 plausible reasons for the dropoff in response. The respondents may have tired of answering the questions and quit. Secondly, some questions in the last part dealt with their perspective of the physician's attitude about herb use; thus, the respondents may not have wanted to answer these questions for fear that their responses may become known to their physician. Consequently, the proportion who felt that their physician will not support their herb use may actually be higher. Because this study surveyed a convenience sample of Hispanics, the responses of these subjects may not be representative of the general population of Hispanics in Indiana. Those who attend health clinics may be less likely to use herbs, thus the estimates of prevalence in this study may be conservative.

Primary care practitioners need to understand the extent and patterns of herbal use by their multiethnic patients and efforts to elicit information from patients about herbal use maybe warranted. ${ }^{37}$ It is important to initiate and encourage open, honest discussion about their patients' interest in or use of herbs. Assessments should start with a thorough drug history, which should include inquiry into the use of dietary supplements including herbs. Pharmacists should strive to provide information routinely on the potential intrinsic effects and interactions of herbs with prescribed medications. Therefore, more continuing education programs and drug information resources about herbal medications must be made available to pharmacists as consumer use continues to escalate. ${ }^{38}$ In addition, therapy guidelines should be clearly defined as in- 
creased knowledge of these adverse factors can help design safer pharmacologic and herbal regimens for individual patients, thus minimizing adverse reactions and promoting good health. Lastly, physicians and consumers are encouraged to report suspected adverse effects of herbal products through the Food and Drug Administration Medwatch system (www.fda.gov or 1-800-FDA-1088) ${ }^{4,9}$ and available at http://www.cfsan.fda.gov/ dms/ supplmnt.html.

It is an obligation of clinicians to elicit information on the use of herbs that may influence their patients' health and to provide information on safe and effective treatment options. It is paramount for clinicians to be aware of known or potential herbdrug interactions to adequately treat their patients. Both physicians and consumers must become more educated about the safe and effective use of herbs. Asking patients about supplement use during an initial history should be made a central component of patient care and medication use monitoring. ${ }^{35}$

\section{References}

1. Eisenberg DM, Kessler RC, Foster C, et al. Unconventional medicine in the United States. N Engl J Med 1993;328:246-52.

2. Eisenberg DM, Davis RB, Ettner SL, et al. Trends in alternative medicine use in the United States, 1990-1997. JAMA 1998;280:1569-75.

3. Elder NC, Gillcrist A, Minz R. Use of alternative health care by family practice patients. Arch Fam Med 1997;6:181-4.

4. Winslow LC, Kroll DJ. Herbs as medicines. Arch Intern Med 1998;158:2192-9.

5. Astin JA. Why patients use alternative medicine: results of a national study. JAMA 1998;279:1548-53.

6. Ni H, Simile C, Hardy AM. Utilization of complementary and alternative medicine by United States adults. Med Care 2001;40:353-8.

7. Dole EJ, Rhyne RL, Zeilmann CA, et al. The influence of ethnicity on use of herbal remedies in elderly Hispanics and non-Hispanic whites. J Am Pharm Assoc 2000;40:359-65.

8. Sleath B, Rubin RH, Campbell W, et al. Ethnicity and physician-older patient communication about alternative therapies. Altern Complement Med 2001; 7:329-35.

9. Boullata JI, Nace AM. Safety issues with herbal medicine. Pharmacol Ther 2000;20:257-69.

10. Druss BG, Rosencheck RA. Association between use of unconventional therapies and conventional medical services. JAMA 1999;282:651-6.

11. O’Hara M, Kiefer M, Farrell K, Kemper K. A review of 12 commonly used medicinal herbs. Arch Fam Med 1998;7:523-36.

12. D'Arcy P. Adverse reactions and interactions with herbal medicines, I: adverse reactions. Adv Drug React Toxicol Rev 1991;10:189-208.

13. Fugh-Berman A. Herb-drug interactions. Lancet 2000;355:134-8.

14. Gordon SM. Hispanic cultural health beliefs and folk remedies. J Holist Nurs 1994;12:307-22.

15. Klepser TB, Klepser ME. Unsafe and potentially safe herbal therapies. Am J Health-Syst Pharm 1999; 56:125-38.

16. Miller LG, Murray WJ. Herbal instruction in United States pharmacy schools. Am J Pharm Educ 1997;61:160-2.

17. Zeilmann CA, Dole EJ, Skipper BJ, et al. Use of herbal medicine by elderly Hispanic and non-Hispanic white patients. Pharmacotherapy 2003;23: 526-32.

18. Hamilton WR, Monaghan MS, Turner PD. A comparison of pharmacy practitioner and pharmacy student attitudes toward complementary and alternative therapies in a rural state. Am J Pharm Educ 2002; 66:55-8.

19. Zenk SN, Shaver JLF, Peragallo N, et al. Use of herbal therapies among midlife Mexican women. Health Care for Women Inter 2001;22:585-97.

20. Ferguson WJ, Candib LM. Culture, language, and the doctor-patient relationship. Fam Med 2002;34: 353-61.

21. Murguia A, Zea MC, Reisen CA, Peterson RA. The development of the cultural health attributions questionnaire (CHAQ). Cultur Divers Ethnic Minor Psychol 2000;6:268-83.

22. Lipton RB, Losey LM, Giachello A, et al. Attitudes and issues in treating Latino patients with type 2 diabetes: views of healthcare providers. Diabetes Educ 1998;24:67-71.

23. Chesney AP, Thompson BL, Guevara A, Vela A, Schottstaedt MF. Mexican-American folk medicine: implications for the family physician. J Fam Pract 1980;11:567-74.

24. Larkey LK, Hecht ML, Miller K, Alatorre, C. Hispanic cultural norms for health-seeking behaviors in the face of symptoms. Health Educ and Behav 2001; 28:65-80.

25. Murguia A, Peterson RA, Zea MC. Use and implications of ethnomedical health care approaches among Central American immigrants. Health and Soc Work 2003;28:43-51.

26. Mendoza M, Peterson MC. New Latino immigration to Tennessee: practicing culturally sensitive health care. Tenn Med 2000;10:371-6.

27. Borrayo EA, Jenkins SR. Feeling frugal: socioeconomic status, acculturation, and cultural health beliefs among women of Mexican descent. Cultur Divers Ethnic Minor Psychol 2003;9:197-206. 
28. Mendelson C. Health perceptions of Mexican American women. J Transcultur Nurs 2002;13:210-17.

29. Davis RE. Understanding women's experiences with pharmacopeia. Health Care for Women Inter 2002; 18:210-17.

30. Bharucha DX, Morling BA, Niesenbaum RA. Use and definition of herbal medicines differ by ethnicity. Ann Pharmacother 2003;37:1409-13.

31. Adler SR, Fosket JR. Disclosing complementary and alternative medicine use in the medical encounter: a qualitative study in women with breast cancer. J Fam Pract 1999;48:453-8.

32. Lee A, Chui PT, Aun CST, Gin T, Lau ASC. Possible interaction between sevoflurane and aloe vera. Ann Pharmacother 2004;38:1651-4.

33. Natural Medicines Comprehensive Database. Available at http://ezproxy.butler.edu:2124/(bofkw055 gbk2 aybln2fyj0y1)/home.aspx?li $=1 \&$ st $=2 \& \mathrm{cs}=$ mlatrial\&s $=$ ND.
34. Methodist Medical Group Pharmacies-A Clarian Health Partner. Herbal Products and SupplementsQuick Reference Guide. Indianapolis, IN. July 2005.

35. Cohen KR, Cerone P, Ruggiero R. Complementary/ Alternative Medicine Use: Responsibilities and implications for pharmacy services. P\&T 2002;27: 440-6.

36. Planta M, Gundersen B, Petitt JC. Prevalence of the use of herbal products in a low-income population. Fam Med 2000;32:252-7.

37. Quo GM, Hawley ST, Weiss LD, Balkrishnan R, Volk RJ. Factors associated with herbal use among urban multiethnic primary care patients: A crosssectional survey. BMC Complement Alt Med 2004; $12: 4-18$.

38. Chang ZG, Kennedy DT, Holdford DA, Small RE. Pharmacists' knowledge and attitude toward herbal medicine. Ann Pharmacother 2000;34:710-5. 